http://dx.doi.org/10.12795/PH.1989.v04.i02.07

\title{
TOPONIMIA RURAL SEVILLANA: EL CASO DE PILAS
}

Catalina Fuentes Rodríguez

Universidad de Sevilla

\section{Introducción.}

La lengua nunca puede estudiarse fuera de su contexto, ya sea el social, el empírico o el histórico. Los acontecimientos históricos van dejando sus huellas en el habla de la comunidad, de forma que, muchas veces, el único testimonio que nos queda de antiguos estadios está en algunas formas lingüísticas conservadas. Así sucede con la toponimia, material de incalculable valor para establecer la evolución lingüística y social de los pueblos.

En este último siglo han avanzado muchísimo los estudios de este tipo. También en nuestro ámbito hispalense hay algunas aportaciones, incluso recientes ${ }^{1}$. Por nuestra parte, intentamos exponer el material recogido en un pueblo de la provincia de Sevilla, Pilas ${ }^{2}$, limitándonos a la toponimia rural, menos estudiada y bastante rica. Pretendemos sólo aportar datos para lo que en un futuro, tras los necesarios trabajos parciales, pueda ser un estudio global sobre la historia lingüística de nuestra provincia.

1 Cfr. Ma D. Gordón Peral: Toponimia de la Sierra Norte de Sevilla -Publicaciones de la Universidad de Sevilla, 1988. Y de la misma autora: «De toponimia hispalense»-Philologia Hispalensis, II, 1, 1986, pp. 141-151.

2 Pilas es un pueblo de la provincia de Sevilla, perteneciente al partido judicial de Sanlúcar la Mayor. Limita con Villamanrique de la Condesa, Aznalcázar, Carrión e Hinojos, este último de la provincia de Huelva. Su extensión es de 4603 hectáreas de terreno, fundamentalmente de secano. Es un terreno llano casi en su totalidad, situado en una colina.

Como estudios sobre la zona cabe reseñar los dos de E. Camacho Rueda: Propiedad y explotación agrarias en el Aljarafe sevillano: el caso de Pilas (1760-1925), Sevilla, Excma. Diputación de Sevilla, 1984. Y «Reparto de tierras y agitaciones campesinas. Pilas, 1821-1839» Archivo Hispalense, 198, 1982, pp. 133-153. 
Al lado de la investigación sociolingüística que actualmente se lleva a cabo sobre la ciudad de Sevilla, y el interés creciente por la relación andaluz-español de América, puede ser también interesante abordar las etapas anteriores de nuestra lengua, tal como ha quedado reflejado en nombres que han pervivido a lo largo de los siglos.

En esta exposición seguiremos la clasificación de topónimos más generalizada, distinguiendo entre macro y microtoponimia, y clasificándolos según campos semánticos. Dentro de cada grupo el orden será alfabético.

Por último abordaremos algunas consideraciones fonéticas y morfosintácticas que surgen del material reseñado. Las explicaciones semánticas (motivación popular, metáfora, metonimia...) van en la explicación de cada término ${ }^{3}$.

Es, pues, otro enfoque de nuestra habla andaluza, vista a través de los nombres fosilizados. Precisamente esta fosilización nos permite darnos cuenta de la fonética y sintaxis de la zona, así como de influencias de otras lenguas o dialectos, en distintos estadios de nuestra historia.

\section{Macrotoponimia.}

Incluimos en este apartado los nombres de lugares habitados, que en nuestro caso se reducen al del núcleo de población sometido a estudio, así como algún otro agregado. El principal es Pilas, nombre actual que ya el Diccionario de Santano y León ${ }^{4}$ recoge. Su origen, según Corominas, está en el latín PĪLA, «mortero», «tina de batán», derivado de PINSERE, «majar» ${ }^{5}$, hoy con el significado de «fuente común para surtirse de agua», «fuente en general» ( $D E C H$, s.v.), a consecuencia «del carácter rudimentario de las pilas en la América colonial» ( $D E C H$, s.v.). Por lo tanto, su nombre respondería a la existencia de muchas pilas a lo largo de todo el término municipal, como muestran mapas antiguos de la zona. La denominación antigua era Pililla (s) de las cuatro torres, derivado mediante un sufijo, al que acompaña un incremento nominal, «de las cuatro torres». Este nombre también responde, según los informantes, a una motivación extralingüística: la población quedaba limitada entre cuatro torres altas dispuestas a cada esquina del pueblo, límites que han quedado superados hoy y en algunos casos han desaparecido.

Dentro del casco urbano hay un agregado rural, hoy absorbido por el núcleo mayoritario de la población: el llamado Barrio de las Varetas o Cerro de los Piojos. Este doblete léxico responde a una misma realidad toponímica debido a la expansión de la población. El más antiguo de los dos es el segundo, Cerro de los Piojos (o del Piojo). La primera parte de este sintagma responde a una clara rea-

3 No siempre hemos podido hallar el elemento léxico originario o la interpretación exacta, aun con la ayuda de las encuestas realizadas a personas de la zona.

4 D. Santano y León: Diccionario de gentilicios y topónimos, Madrid, Paraninfo, 1981.

5 J. Corominas-J.A. Pascual. Diccionario crítico-etimológico castellano e hispánico, Madrid, Gredos, 1981, s.v. (Citado DECH). 
lidad oronímica, mientras que la segunda parte se debe a una denominación popular, debido a la costumbre de espulgar a los niños en la puerta de la casa.

El otro miembro del doblete, elemento también compuesto, Barrio de las Varetas, comprendía originariamente lo que era el Cerro de los Piojos y su desarrollo posterior. En ese el incremento nominal, de las Varetas, se debe también a una motivación extralingüística: se trataba de una serie de solares que se vendieron para su edificación y cada vecino lo cercó con varetas ${ }^{6}$. Este término es un derivado de vara mediante un sufijo pretendidamente oriental. Está documentado en 1604 (DECH, s.v.). Según la Academia es «palito delgado, junco o esparto que, untado con liga, sirve para cazar pájaros» ${ }^{7}$. Y para Alcalá Venceslada corresponde a «pleita de cinco manojos, que a diferencia de los de la crineja no se tuercen al tranzarlos» (Prov. de Jaén) ${ }^{8}$. Sin embargo, en nuestro caso este diminutivo se usa con el valor de «palo delgado de rama de olivo», similar a la entrada vargueta que recoge Alcalá Venceslada.

Otros agregados de la población recientes corresponden a urbanizaciones : La Cámara, La (s) Lamaparilla (s) (antigua finca del mismo nombre), Los Ventolines y La Soledad. En el primero el apelativo base parece tener el significado que

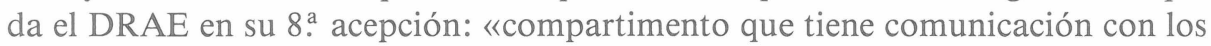
hornos metalúrgicos, para condensar o transformar las sustancias volatilizadas» (DRAE, s.v.), aunque trasladado. Este nombre se debía, según los informantes, a la existencia de una "cámara de ladrillos», es decir, un horno en forma circular. Esa motivación original ha desaparecido, manteniéndose el nombre como designación de lugar, ya desemantizado.

La(s) Lamparilla(s) era un terreno de cultivo, hoy urbanizado. El nombre corresponde a un sufijado diminutivo de lámpara, probablemente con el sentido de «Álamo de hoja temblona por la evocación del parpadeo de la candelilla encendida» (4. ac., DRAE).

En cuanto a Los Ventolines suponemos que es un derivado de viento, con alteración del género. El DRAE y el DECH recogen ventolina «viento leve y variable» (DRAE, s.v.). Ha podido crearse desde aquí el supuesto masculino, ventolín, del que se ha tomado el plural.

Por último, La Soledad, de creación reciente, y motivación religiosa en la denominación (Hermandad de la Virgen de la Soledad).

\section{Toponimia Menor.}

Este grupo de apelativos será clasificado en grupos que responden a las afinidades semánticas que presentan. Así distinguiremos los que sirven para variaciones orográficas, cuestiones relacionadas con el agua, vías de comunicación,

6 Según los informantes, ya que es un núcleo de reciente creación.

7 Real Academia Española: Diccionario de la lengua española, Madrid, Espasa-Calpe, 1984, 20. ed., s.v., 2. acep. (Citado DRAE).

8 A. Alcalá Venceslada: Vocabulario andaluz, Madrid, Gredos, 1980, s.v., (citado VA). 
cultivos, flora, fauna... En suma, todo aquello que rodea la vida rural y que ha sido aprovechado en el transcurso de los siglos para dar nombre a los lugares que rodeaban al ser humano o le pertenecían.

\subsection{Orónimos.}

Recogemos aquí todos aquellos topónimos que hacen alusión a características orográficas del terreno, ya sean elevaciones, depresiones, planicies o que simplemente indiquen conformaciones especiales del mismo.

ALTA (Roza alta $)^{9}$.

CAMPILLO (El Campillo), disminución de campo y forma muy frecuente en nuestra toponimia.

CERRO (Cerro del Grullo). La poca abundancia de topónimos con este nombre revela lo igualado del terreno. El topónimo en que entra presenta un complemento de origen metafórico, lo mismo que en el macrotopónimo Cerro de los Piojos, antes citado.

LOS CUADROS. De Cuadro. Su sentido es «cuadrado o rectángulo (aplicado esp. a las obras de arte pintadas, a porciones de tierra labrada, etc)» (DECH, s.v.) LA ESCUADRA. Derivación de la forma anterior.

HOYO (Hoyo del Huerto). Derivado de hoya por diferenciación genérica. Ambos se refieren a concavidades del terreno, si bien el elemento femenino alude a una concavidad más grande y natural, mientras que el hoyo es pequeño y puede ser intencionado, realizado por la mano del hombre: «sacado de hoya en calidad de forma diminutiva, por analogía de pozo _poza, charco _charca» ( $D E C H$, s.v.). El topónimo que tenemos está acompañado de una especificación referida al terreno de cultivo de ese lugar.

LOMA (Loma de la Ventura).

LAS LONGUERAS. Derivado de luengo, «largo», forma antigua del latĩn LONGUS. A propósito de Longuera nos dice Corominas: «Llongueres es frecuente en la toponimia catalana, y formas parecidas están bien representadas en Italia y el Friul» (DECH, s.v. luengo).

MONTE (Montes de Doña Isabel, Montecabillos). Los dos topónimos que encontramos con este término son de formación muy distinta. El primero de ellos tiene un antropónimo con resonancias histórico-sociales. El otro es más usual; su segundo elemento es un derivado de cabo. Su significado es «pezón, rabillo, pedúnculo». Por lo tanto, semánticamente tienen afinidad.

\section{LA PEÑA.}

LA PLATA, término muy frecuente en la Sierra Norte ${ }^{10}$ como reminiscencia de la riqueza argentífera de aquella zona. Ignoramos la motivación semántica de este topónimo en nuestra población, donde no hay minas.

9 En mayúsculas va el término que indica esa circunstancia del terreno y entre paréntesis el topónimo en que aparece.

10 Cfr. M. D. Gordón Peral: Toponimia..., citado. 
RABO (Rabo del Asno). El nombre de este topónimo puede ser debido a la forma del terreno, franja alargada, según nuestro informante.

RAYA (Raya de Santillán). Su sentido podría ser el de "Término, confín, o límite de una nación, provincia, región o distrito, y también lindero de un predio si tiene mucha extensión», o bien «vereda ancha que se hace o deja para que se propaguen los incendios» (ac. 2. y 4 . $\operatorname{ar}$ del $D R A E$ ).

VALLE (Valdecabras, Los Valles). Es muy frecuente encontrar topónimos compuestos de val (apócope antiguo de valle) + de + sustantivo. Sin embargo en el segundo topónimo se mantiene la forma plena, la utilizada actualmente como apelativo.

\subsection{Vías de comunicación.}

Incluimos en este apartado todos aquellos topónimos que en su denominación presentan un elemento léxico relacionado con las vías de comunicación. De ahí que haya ocasiones en que no correspondan realmente a ninguna de ellas, sino a terrenos de cultivo que han tomado su nombre por el del camino que llevaba a ellos. Así ocurre, por ejemplo, con Las Carreras o Carramolo. En cuanto a la extensión del apartado, comprende todo tipo de vías, ya sean rurales, de ganados u otro tipo, desde veredas, restos de carrriles...

CAMINo (Camino del Cementerio, C. de Chucena, C. de Hinojos al Perú, C. de HInojos a Carrión, C. de Escacena, C. de Huévar, C. De Benacazón, C. de Aznalcázar, C. Viejo de Sevilla, C. de Bollullos, C. de la Venta, C. de la Marisma, C. del Rocío, C. de los Carboneros, C. Real de los Isleños, C. Real del Carrascal). En estas construcciones nominales el incremento sustantivo corresponde a un macrotopónimo, referido a los pueblos de alrededor, o con los que se tenía comercio, o bien a microtopónimos de lugares a los que llevaban: la Venta, la marisma, el cementario, el Carrascal. Hay otros que contienen referencias sociohistóricas: Camino de los Carboneros (el que tomaban los carboneros para ir a la ciudad), Camino Real de los Isleños (para ir a la Isla, un pueblo relativamente alejado de Pilas).

CAÑADA (Cañada del Zarco, C. de don Luis, Las Cañadas, C. de los perales). Los incrementos que lleva constan de una referencia antroponímica o de la flora o fauna.

CARNE (Vereda de la Carne). Incluimos este término ya que tiene el sentido de «camino para animales», y se localiza también en la Sierra Norte ${ }^{11}$.

CARRAMOLO. Compuesto de carra, «camino» (DECH, s.v. alcarria), a su vez una síncopa del ant. carrera ( < lat. *CARRARIAM), "frecuentemente empleado en nombres de lugar compuestos» ${ }^{12}$. El otro miembro molo, es para Corominas, una forma italiana de MOLES muelle, que pasó al castellano localmente. También podría postularse que respondiera a una deformación de MŪLUS >

11 Ídem.

12 J. A. Frago García: Toponimia del Campo de Borja: Estudio lexicológico, Zaragoza, Inst. «Fernando el Católico», 1980, p. 73. 
mulo. De esta manera sería «camino de mulos», sentido que parece encajar mejor en la realidad toponímica, y con el que lo relacionan los informantes.

LAS CARRERAS. Término del mismo origen del anterior, y con el valor de «camino para carros».

CARRETERA (C. de Hinojos, C. de Villamanrique, C. de Aznalcázar, C. de Carrión). Derivado del lat. CARRUS, de procedencia gala, «Carro». De ahí carreta y carretera, «camino» (DECH, s.v. carro). Pero sufrió un cambio semántico con el cambio de realidad: los caminos fueron asfaltados. Los topónimos que tenemos son de creación reciente, y se componen de macrotopónimos alusivos a los pueblos que rodean a Pilas.

LAS CRUCES. Según T. Buesa ${ }^{13}$ es el nombre más usado para indicar bifurcación de caminos.

CUESTA (Cuesta de Robadina), «terreno en pendiente» según el DRAE (s.v.).

PUENTE ( $P$. de Robadina, $P$. de Santillán, $P$. de Hinojos, $P$. de la Junta, el Pontón). Los nombres de lugar se componen de otros microtopónimos, referentes a zonas cercanas al arroyo. Sólo un nombre hace referencia a una institución: Puente de la Junta. El Pontón se refiere al puente que limita el pueblo con el siguiente: Aznalcázar. Es un sufijado aumentativo. Sin embargo, parece haberse perdido conciencia de esa formación, ya que el Pontón es topónimo de toda la zona que rodea a dicho puente.

VADERA. Derivado de vado mediante el sufijo - era. Su sentido es «vado, especialmente el ancho por donde suelen pasar ganados y carruajes». (DRAE, s.v.). Actualmente ese valor primario ha desaparecido de la conciencia de los hablantes.

VEREDA (V. de Ganados, V. Real de la Carne, Veredilla Chica, la Vereda). Término bastante corriente en la toponimia, sobre todo el segundo, que indicaba la vía seguida por todos los ganados trashumantes.

VÍA (Casilla de la Vía). Originariamente «camino», «carretera», «calle», «viaje» (DECH, s.v.), hoy también con el valor de «raíl del ferrocarril» (4. acep. del DRAE), utilizado aquí. Es un nombre reciente, pues, que ha sufrido una traslación semántica por cambio de la realidad.

\subsection{Terreno cultivado y acotado. Medidas del terreno.}

En este apartado aprecen topónimos alusivos a los tipos de terreno, ya sea por la clase de cultivo, o por estar acotado o no y de alguna forma en especial, así como con características especiales (Chilla). Hay otros que se refieren a medidas: las Cuarenta (aranzadas).

ARANZADA (Las Veinte, Granja de las Veinte, Las Cuarenta). Topónimos originados por la elipsis de este sustantivo que designa una medida agraria (derivado de arienzo < ARGENTEUS, moneda y peso antiguos).

13 Cfr. T. Buesa Oliver: «Significantes de 'bifurcación de caminos‘ en las hablas de Aragón, Navarra y Rioja» Mélanges de Philologie et de Toponimie Romanes offerts a H. Guiter, Perpignan, 1981, pp. 187-212. 
LOS ASIENTOS. El valor de este elemento, derivado de sentar, es difícil de determinar. Podría ser «contrato», o «territorio y población de las minas» (acep. 9. y 11. del $D R A E)$. O bien el sentido que el da Alcalá Venceslada. «Labor de aplanamiento del terreno de una viña con la pala de la azada» ( $V A$, s.v.).

EL BALDÍO. Alusión a su antiguo régimen comunal.

BARRERO (B. de Robadina, B. del Pino, B. del Caracolillo). Es un derivado de barro, de origen prerromano, y hace alusión al sitio donde se obtenía este. Lo acompañan designaciones referidas a las zonas de cultivo junto a las que se encuentra.

CALDERA (La Caldereta, Calderón). Tenemos dos derivados, uno diminutivo, y el otro aumentativo, a partir de CALDARIA, derivado a su vez de CALDUS. Puede que se refieran a las formas del terreno. Sin embargo, con respecto a calderón, M. Dolç ${ }^{14}$ lo considera un nombre de oficio. En asturiano tiene también el sentido de «rayuela, juego de muchachos» (DECH, s.v.).

CERCADO (Cercado de Ricote, Cerrado de los Potros). El primero proviene de cercar: terreno con vallas, perteneciente a Ricote, sobrenombre del dueño. El segundo, cerrado, tiene el mismo valor, pero proviene de cerrar. Alcalá Venceslada le da un sentido más específico a ese segundo término: «porción extensa de terreno vallado, dentro de la cual pastan y abrevan las reses bravas» ( $V A$, s.v.), más ajustado, a nuestro parecer, a la realidad toponímica.

CHILLA. De CELLA, «celda», con tratamiento mozárabe, corresponde a lugares donde existen cuevas y yacimientos arqueológicos ${ }^{15}$.

LA CINTA. Corresponde a un terreno situado en la falda del arroyo. Podría tratarse, pues, de una metáfora basada en la forma del terreno.

CORTiJO. (C. de Santillán, C. de la Vivilla, C. de Robadina, C. de Chilla, C. de Espechilla, C. de Jabaco). Según Corominas, se encuentra en un doc. de San Fernando, a.1224, un término del bajo latín: CORTIGIUM, y es «palabra empleada casi exclusivamente, y ya desde antiguo, en Andalucía» ( $D E C H$, s.v.). Para el DRAE es un derivado de corta y su sentido es «posesión de tierra y casa de labor» (1. ac. del $D R A E)$. En consonancia con esto, los topónimos que encontramos en nuestra zona llevan un incremento nominal con el nombre del terreno en que están enclavados.

CUARTO (Cuarto Bajo de Robadina). Alusión a la partición de la dehesa entre varios propietarios ${ }^{16}$.

LA DEHESA. En los documentos consultados aparece con el signo del ceceo propio de la zona: Deeza ${ }^{17}$, y con la aspiración Heza ${ }^{18}$. Según Corominas hoy se pronuncia «jesa o hesa con $h$ aspirada en muchas localidades de Salamanca y Cáceres» (DECH, s.v.). Hay que extenderlo, pues, a nuestra zona.

14 M. Dolç: Antroponimia latina, E.L.H., I, Madrid, C.S.I.C., 1960, pp. 389-419, en p. 415.

15 Cfr. E. Camacho: Propiedad... op. cit., pp. 134-6.

16 Cfr. M. D. Gordón: «De toponimia hispalense», cit, pp. 148-9, donde estudia el término.

17 Documento de 1823, folio 65, en el «Repartimiento de las tierras del Baldío de Argento y sitio del Chaparral con real aprobación».

18 En un documento de 1734, folio 37 del «Libro de Fincas y Propiedades de este Cabildo de 1585 en adelante». 
ERA (Pinar de la Era, Cinco Eras). Por existencia de lugares de trilla en otros momentos, hoy inexistentes.

FERIA.

LA HAMBRE. Según nuestro informante, está motivado por una metonimia: causa-efecto: al estar muy alejado del pueblo, producía hambre a los que iban a trabajar, ya que debían hacer el camino a pie.

HUERTO, -A (Hoyo del Huerto, Huerta de Lope, H. de la Lilla, H. de la Concha, $H$. de Hipólito, $H$. del Pilar, H. del Marqués, H. de Miguelera, H. de los Morenos, $H$. de la Macarena, $H$. de Ascensión, $H$. de Juan $M^{a}$ el de la Pelaya, H. de los Barbis, H. de Fernando de Burgos, H. de Chone, H. de Remigio, $H$. de Capotito, H. del Padre Sánchez, H. de Manolije). Tenemos dos elementos con diferenciación genérica. El primero aparece con un orónimo, y el segundo con antropónimos.

LO (Lo de Perico Cela, La de Mi Ana). Artículo usado en función nominalizadora de construcciones adjetivas. Puede suponerse la elipsis de uno de los elementos incluidos en este apartado: huerta, terreno...

MARISMA (Camino de la Marisma). Referente a la Marisma de Huelva, terreno comunal.

EL TEJAR. Referencia a un antiguo lugar donde se fabricaba tejas y ladrillos, hoy desaparecido.

\subsection{Hidronimia.}

Variados son los elementos que se incluyen bajo este epígrafe. Por una parte, están los referidos a lugares rurales donde se encontraba el agua. Por otra, tenemos nombres que responden al desagüe de la ciudad: Alcantarilla, Gavia. Otros elementos han sido motivados por circunstancias orográficas e históricas: Laguna de Cantagallo. Y por último aparecen apelativos de tipos de terrenos que han tomado su nombre específico por ser colindantes con un arroyo. Así Lastre, Playas o Robadina, por ejemplo.

ALCANTARILLA. Diminutivo de alcántara, «puente» (arabismo) (DECH, S.v. alcántara).

ARROYO (A. de Alcarallón, A. de Hinojos o de Muré). Término de origen Prerromano. ( $D E C H$, s.v.).

FONTANAL. Para Corominas es un derivado de fontana (este proveniente de FONTANA AQUA, «agua de fuente»), mantenido en la toponimia con la finicial. La palabra que hoy tenemos en español es hortanar, colectivo que se usa como término poético. Este mismo autor cita fontanal como «lugar de fuentes» ( $D E C H$, s.v. fuente) en Nebrija. En nuestro caso, está tomado metonímicamente: lugar abundante en agua.

FUENTE (del Puerco). Referente al lugar donde se bañaban los cerdos que recogía un porquero comunal.

LA GAVIA. Término recogido con el sentido que tiene en la zona por J. Fernández Sevilla ${ }^{19}$. Este autor lo registra en Sevilla y Cádiz y lo deriva de CA-

19 J. Fernández Sevilla: Formas y estructuras en el léxico agrícola andaluz, Madrid, C.S.I.C., 1975. 
VEA, «hoyo», «desde aquí pasó a 'hoyo hecho en la tierra' y a 'zanja', de donde 'zanja para conducir el agua'. El DRAE recoge acepciones afines, entre ellas 'zanja que se hace en la tierra para desagüe o linde de propiedades'; en cambio, no conoce estas acepciones andaluzas Alcalá Venceslada» ${ }^{20}$.

LAGUNA (Laguna de Cantagallo). De motivación popular.

LASTRE. El sentido que reconoce Corominas para este término es «peso de piedra, arena o cosas semejantes, que se pone en el fondo de la embarcación, a fin de que ésta entre en el agua hasta donde convenga», de origen no muy claro. Es perfectamente adecuado a la realidad toponímica ya que es un terreno situado al pie de un arroyo. Por metonimia puede haber tomado el nombre.

LA NORIETA. Formación con diminutivo sobre noria, en este caso la noria que surtía al pueblo de agua.

PANIAGUA. Hoy un antropónimo, aunque puede deducirse su origen.

PILA (La Pila, Huerta del Pilar, El Pilar, Pililla(s)). Es sintomático la abundancia de topónimos con esta base y se relaciona con el macrotopónimo de la villa. Dijimos que el nombre más antiguo de esta era Pililla(s). Esto lo confirma la existencia de un terreno con este nombre, en donde se han encontrado cuevas de árabes, lo que parece indicar que era parte de un asentamiento árabe en esta zona. En cuanto a su derivado, pilar, significa «pila grande para beber los animales» (DECH, s.v.).

PLAYAS (Playas de las Mestas, Casa de las Playas). El sentido que tiene no es tanto de ribera de mar o arroyo grande, como le reconoce el DRAE, sino toda tierra arenosa que está cerca de un arroyo, grande o pequeño.

POZO (Pozo del Concejo, Pozuelo). El primero corresponde a una institución: el lugar donde iban a beber los puercos que se recogían por todo el pueblo. El segundo es un diminutivo muy frecuente ( < ÓLUM).

EL REGAJO. Derivado sufijado de riego, palabra de origen prerromano.

ROBADINA (Cuarto Bajo de Robadina, Robadina). Posible derivado de ro$b a d a$, a partir de robar, mediante el sufijo -ina: hecho o acción de robar ${ }^{21}$. Puede referirse a la acción de robar tierra al agua, ya que en este caso corresponde a la tierra que está junto al arroyo. Corominas, sin embargo, lo señala como un derivado del árabe rúkna, «rincón», rukáina. Según él «Dozy documenta ese mismo diminutivo, en sentido especializado, en el Mohit» ${ }^{22}$. Pasaría luego a Rogaina y de ahí a Robaina.

\subsection{Fauna.}

En este apartado se incluyen todas aquellas denominaciones que en su significado hacen referencia a las especies animales, ya sea utilizándolas en sentido metafórico (por ej. Rabo del Asno) o con referencias históricas reales (Valdeca-

20 Ídem, p. 284.

21 M. Álvarez García: Léxico-génesis en español: los morfemas facultativos, Sevilla, Publicaciones de la Universidad, 1979, p. 84. Este sufijo convierte el adjetivo en sustantivo.

22 J. Corominas: Tópica hespérica t. I, Madrid, Gredos, 1972, p. 60. 
bras, Mataperrillos...). O bien algunos nombres relacionados, por ej. Capotito, referido a los toros, afición muy extendida en la zona.

ABUBILLA ( La Vivilla). Podría postularse el origen de vivilla en este término: varios cambios fonéticos han reducido aún más su cuerpo fónico.

ASNO (Rabo del Asno).

CABALLO (Matacaballos). Compuesto de verbo más implemento, que puede haber tenido su origen de manera análoga a Mataperrillos, referente al lugar donde la gente mataba y enterraba los perros, razón primera ya perdida de la conciencia de los hablantes.

CABRA (Valdecabras).

CAPOTITO (Huerta de Capotito). Este término, correspondiente al sobrenombre del propietario de la huerta, es un diminutivo de capote, y este un derivado de capa. Según Corominas, «se hace difícil decir en qué lengua romance nació este derivado de capa» (DECH, s.v.). Hay testimonios en catalán y occitano, pero los castellanos son más antiguos, aunque no parece ser autóctono. Este término también sobrevive como onomástico. Actualmente, su principal valor, el más usado al menos en la zona, es el de «Capa de color vivo, por lo común rojo, algo más larga del capote de paseo, usada por los toreros para la lidia» que corresponde a capote de brega (DRAE, s.v. capote).

CARACOLILLO (Barrero del Caracolillo, El Caracolillo). Diminutivo de caracol, voz de origen incierto. Aparte de este sentido, que podría haberse tomado por diversas razones, también recoge el DRAE otra acepción: «planta de jardín, originaria de América meridional, leguminosa, con tallos volubles, hojas romboidales puntiagudas, flores grandes, blancas y azules, aromática y enroscadas en figura espiral» (2: acep. del $D R A E)$.

ESCORCHADO (El escorchado). Derivado de escorchar, de origen francés o catalán $(D E C H$, s.v. corteza).

GALLO (Laguna de Cantagallo).

GRULLO (Cerro del Grullo). Alcalá Venceslada considera grullo, -lla como «persona rústica» $(V A, \mathrm{~s} . \mathrm{v})$. El origen de grulla como sustantivo está muy discutido. Parece ser una «alteración del antiguo grulla o grúa, procedente del lat. GRŨS, GRUUIS» (DECH, s.v.). La / $\lambda$ / podría explicarse por ser «forma procedente de León o de Aragón, donde existieron focos antiguos de confusión de las dos consonantes» ( $D E C H$, s.v.). Para la explicación de nuestro topónimo podríamos postular un «Cerro de las Grullas» o bien tomar grullo como adjetivo: «Cerro del grullo» (este último sustantivado).

LA LILLA (Huerta de la Lilla). Sobrenombre de la propietaria de la huerta, tiene su origen en el mismo término usado como apelativo en el habla popular de la zona, en la frase «dar lilla a una persona» azuzar. Podría corresponder a «dar lidia», o «dar alillas», pero es sólo una hipótesis. No la hemos encontrado recogida en ningún diccionario, pero los habitantes del pueblo la utilizan en ese sentido.

PERDICES (Venta de las Perdices). De creación popular: en la venta se servían perdices, y estaba adornada con dibujos de estos pájaros.

PERRILLOS (Mataperrillos). 
POTROS (Cerrado de los Potros).

PUERCO (Fuente del Puerco).

RABO (Rabo del Asno).

LA SEÑORITA. Según Alcalá Venceslada puede ser «culebra de pequeñas dimensiones» ( $V A$, s.v.). O bien referirse a su antigua propietaria, con resonancias socioculturales entonces (de desigualdad social).

ZARCO (Cañada del Zarco). Del árabe vulgar ZÁRQA (clásico ZARQÂ'), femenino de 'ÁZRAQ, azul ${ }^{23}$. El sentido que recoge el DRAE es: «De color azul claro Ú. Hablando de las aguas, y, con más frecuencia, de los ojos» (DRAE, s.v.). Alcalá Venceslada, sin embargo, nos da otro sentido: "Caballería que tiene en los ojos un círculo claro alrededor de la retina» ( $V A$, s.v.). En ambos es adjetivo. Luego el uso que aparece en el topónimo es el de un adjetivo sustantivado, motivado por alusión a alguna característica del dueño o de un animal perteneciente a él. De todas maneras la denominación es antigua. Aparece en los primeros documentos. Así en el folio 9 de un documento de $1611^{24}$. Sin embargo, E. Camacho Rueda cita una Cañada del Sarco ${ }^{25}$. Podría tratarse, pues, de un ceceo y la palabra significaría «sayo de faldamenta larga» (DRAE, s.v.). En este caso podría tratarse de una metáfora basada en la forma del terreno.

\subsection{Flora.}

Caben aquí todas las referencias a especies cultivadas en el lugar, aunque no se mantengan. En algunos casos la conciencia de este origen se ha perdido y es difícil encontrar su conexión con los cultivos. Así, nuestros informantes desconocían la motivación de El Mantuar, término que hemos propuesto derivado de mantúa, tipo de uva, que sí es conocido en el lugar. Otro nombre que hemos incluido es Roza alta, que en un principio pensamos que se trataba de Rosa(s) Alta(s), porque así aparecía en el mapa de la Hermandad de Labradores y Ganaderos. Sin embargo, nuestros informantes lo conectan más bien con el verbo rozar, con lo cual el ceceo, que parecía advertirse no era tal, sino su pronunciación académica, confusión debida a la neutralización de esa pareja de sibilantes en el habla de Pilas. A continuación exponemos y explicamos los términos:

ALCARAYÓN (Arroyo de Alcarayón). Una posible etimología podría ser Alcaraçón, forma aragonesa dẻ carrazón, «romana», que se encuentra en un inventario aragonés de 1404. Podría tratarse de una confusión de palatales antes del reajuste y de la existencia en nuestra toponimia de un término de origen aragonés, aunque podría derivar de la misma palabra árabe. Cabe también otra posibilidad: derivar de alcaravea, que tuvo varias vocalizaciones. En val. ant. tenemos: alcarahuya, alcarahulla, y en arag. ant. alcarahueya citamos por Corominas. En este caso sería un aumentativo, y de ahí que lo incluyamos en este apartado.

23 J. Corominas: Breve diccionario etimológico de la lengua castellana, Madrid, Gredos, 3a ed. 196, p. 623, s.v. zarco.

24 Libro de propiedades de 1611.

25 E. Camacho: «Reparto...», op. cit., p. 140. 
AULAGAR (Abulagar). Derivado de aulaga, «probablemente de origen hispánico prerromano» ( $D E C H$, s.v. aulaga).

CARRASCAL (Camino del Carrascal, El Carrascal). Derivado de carrasca, «encina, generalmente pequeña» ( $D E C H$, s.v.). También nos dice Corominas que puede referirse a un tipo de olivos.

CHAPARRAL (El Chaparral, Los Chaparrales). Derivado locativoabundancial de chaparra, variante genérica de chaparro, también de origen prerromano.

CHOCHAL.

ESTACADA (Estacada de Resinas, Estacada del Gallego). Sufijado de matiz semántico aumentativo con respecto a estaca. Para Alcalá Venceslada es «olivar nuevo» $(V A$, s.v.) y el DRAE lo define como «olivar nuevo o plantío de estacas» (4. ac.). Acompañan a este sustantivo dos ampliaciones referidas a sus dueños por sus apelativos o sobrenombres.

LOS GARABATOS. Según Corominas puede ser un derivado del asturiano y santanderino "gárabu, gáraba», "palito», de la misma familia prerromana que CARBA, «rama, matorral», «rebollo» (DECH, s.v.). Los sentidos de este término son muy diversos. Ignoramos cuál es el que tiene aquí.

EL GRANADAL.

EL MANTUAR. Puede tratarse de un sufijado locativo-abundancial de mantúa, «clase de uva, común en el condado de Niebla» (VA, s.v.).

MELGAREJO. Aparece en el Diccionario de Topónimos como un gentilicio de Melgar (Colombia) ${ }^{26}$. Por su parte, este melgar aparece en Corominas como un derivado de mielga, «campo de mielga frecuentísimo como nombre de lugar» (DECH, s.v.). Mielga es «planta forrajera, especie de alfalfa» (DECH, s.v.).

OLIVAR (Palmera de Olivar y Casa, Casa del Olivar).

EL PALANCAR. De palanca, pero no se recoge el derivado en el DRAE.

PALMERA (Palmera de Olivar y Casa). Tomada del catalán como derivado de palma.

PERAL (Cañada de los Perales).

PINO (Pino de Santillán, El Pinar de la Era, Barrero del Pino).

ROZA (Roza Alta). Derivado de rozar. Su sentido es «tierra rozada y limpia de las matas que naturalmente cría, para sembrar en ella», o «acción y efecto de rozar», (ac. 3. y 1. del DRAE).

\subsection{Antroponimia.}

Es el grupo más numeroso de denominaciones. Por un lado, están aquellos que hacen referencia a características humanas, ya sean profesiones o bien adjetivaciones de tipo antropomórfico. En un segundo grupo aparecen designaciones que tienen resonancias socio-históricas: Los judíos o el Marqués, ya indiquen antiguos asentamientos, o el sistema social imperante durante mucho tiempo en el pueblo. Y, por último, una lista de nombres propios, onomásticos que a veces son los sobrenombres o apodos de la familia. 


\section{A) Caracterización humana:}

LA AUTORA.

LA CALERA (Venta del Calero, La Calera). Derivado de cal, usado como nombre de oficio.

CARBONEROS (Camino de los Carboneros).

CONEJERO.

ENANA (Las Nanas). La forma que aparece con aféresis de $e$ - con respecto al español general, va más de acuerdo con su origen: NANAS (de NANUS, -A, -UM). Enano, según Corominas-Pascual, es alteración, «quizá debida al influjo del antiguo enatio, 'deforme“»(DECH, s.v.).

GALLEGO (Estacada del Gallego). Gentilicio.

GITANA. Hace referencia a la raza que convive con la tradicionalmente residente en la zona. Proviene de egiptano y tiene gran uso no sólo para referirse a estas personas, sino también en el sentido de elogio para una mujer, valor que aparece en el Diccionario académico.

ISLEÑ̃S (Camino de los Isleños). Derivado gentilicio a partir de isla. Procedente de un pueblo de los alrededores.

LA MACARENA. Hoy es onomástico y apelativo, adjetivo: «vecino del barrio de la Macarena, en Sevilla» (1. ac. del DRAE). También tiene el sentido de «guapo, majo, balandrón» (2. acep. del DRAE).

MANOS LLENAS.

MENSONERA. Posible variante de mesonera, derivado de mesón.

MORENO (Huerta de los Morenos, Granja de los Morenos). Sobrenombre de los propietarios. Han utilizado una característica antroponímica, que podría estar motivada en su origen.

PANADERA.

LA SEÑORITA. Véase en 3.5.

URBANO (Venta Urbano). Su origen están en un adjetivo derivado de urbe. B) Resonancias socio-históricas:

DOÑA ISABEL (Montes de Doña Isabel).

LOS JUDÍOS. Este topónimo tiene una gran resonancia histórico-cultural pues hace referencia al pueblo que estuvo extendido por muchas partes de España. Aunque en Andalucía la toponimia árabe puede ser mucho mayor, también hallamos este término. Sin embargo, según nuestro informante, correspondía a una zona que colindaba con el pueblo y que por sus malas condiciones de vida podría servir para asustar a los niños. Se mantiene, pues, la tradición popular.

DON LUIS (Cañada de Don Luis). Se conserva el don, al igual que en el primer topónimo de este apartado, distinguiéndolo así de otros propietarios: nombre propio + don / sobrenombre + artículo.

MARQUÉS (Huerta del Marqués). En este caso es el título social el que distingue este propietario de los otros. Topónimo de marcado valor sociocultural, que continúa a pesar de que la realidad cambia. Hace referencia a la antigua situación del pueblo que estaba casi totalmente en manos de grandes propietarios o señores de la nobleza. 
PADRE SÁNCHEZ (Huerta de Pá Sánchez). Pérdida de la sílaba final en padre, término utilizado para referirse a los sacerdotes, hoy en desuso, al menos en nuestra zona. Era habitual este apócope.

PERÚ. Nombre alusivo a la aventura americana. Su motivación posible podrá estar en que es una finca bastante alejada del pueblo y los trabajadores no tenían medio de transporte.

LA VENTURA. Posible motivación en una leyenda o augurio. O bien, podría tratarse de la Aventura.

C) Onomástica personal:

ALEMANIA (Venta Alemania o Venta Alemana). Topónimo de reciente creación, señala las huellas de la emigración en la zona.

ANA (La de Mi Ana).

ASCENSIÓN (Huerta de Ascensión).

BARBI (Huerta de los Barbis). Sobrenombre de los propietarios.

BELICO (Venta de Belico). Sobrenombre.

BERLANGA. De VALERIANICA, apellido y nombre de lugar. Santano y León lo documentan en Badajoz ${ }^{27}$ y Corominas en la provincia de Soria $(D E C H$, S.v.).

CONCHA (Huerta de la Concha). Abreviatura afectiva de Concepción, apelativo y antropónimo. Nótese, como en otras ocasiones, el artículo que precede, como en el lenguaje vulgar, a estos nombres.

CHONE (Huerta de Chone). Sobrenombre del propietario. Puede tener relación con chon. «En la frase 'hacer chon' es usada por los niños en los juegos del tejo y de la formilla o cuando meten todos los volantines o botones en un agujero. Con ello se gana» ( $V A$, s.v.). Puede ser un plural, en que ha desaparecido, tras la aspiración, la -s final.

FERNANDO DE BURGOS (Huerta de F. B.). Onomástico al que sigue un topónimo que marca el origen de la familia.

HIPÓLITO (Huerta de Hipólito).

JABACO. Sobrenombre antiguo.

JUAN MARÍA EL DE LA PELAYA (Huerta de J.M.P.).

LOPE (Huerta de Ope). Suponemos que es una abreviación de Lope.

MANOLIJE (Huerta de Manolije). ¿Contracción de Manolo hijo?

MARIANA (Las Marianas).

MIGUELERA (Huerta de Miguelera). Sobrenombre del propietario. Derivado de Miguel.

MURÉ. (Arroyo de Muré). Ignoramos su origen, aunque podría ser una alteración de Muriel. También aparece transcrito a veces Mures.

PANIAGUA. Apellido español. Responde a un propietario de la finca, Juan Paniagua, al que encontramos mencionado en los documentos ${ }^{28}$.

PERICO (Lo de Perico Cela). Perico es derivado diminutivo afectivo y antiguo de Pero (Pedro). Cela es apellido aún hoy corriente.

27 Ídem, p. 299, s.v. Berlanga.

28 Folio 58 de un documento de 1823. 


\section{LA PITIFLA.}

REMIGIO (Huerta de Remigio).

RESINAS (Estacada de Resinas). Puede ser alusivo a un antiguo propietario terrateniente de la localidad: D. Francisco José Resinas ${ }^{29}$.

SANTILlán (Pino(s) de Santillán, Cortijo de Santillán). Onomástico medieval de SANCTUM JULIANUM.

Otros topónimos de difícil explicación y clasificación son ESpijarrilla, Espechilla y Esperlilla, que incluimos aquí como apéndice, como posibles sobrenombres. Tampoco nuestros informantes reconocen su origen.

\subsection{Construcciones.}

En este grupo aparecen lugares construidos, normalmente fuera del pueblo, habitados o no. Por su especificidad, pensamos que era preciso un capítulo aparte. En ellos es posible ver la evolución de la vida social del pueblo, ya que son construcciones con diversos motivos y utilidades.

CASA (Casablanca, Palmera de Olivar y Casa, Casa de las Playas, Casa de la Huerta, Casa del Olivar, Casa del Pozuelo, Casilla de la Vía). Tenemos un elemento en construcción nominales; en un compuesto: casablanca, y un diminutivo: casilla.

CEMENTERIO.

CHALÉ (Chalé de las Veinte).

LA COOPERATIVA, topónimo de creación reciente, derivado de cooperar, cultismo. Es un adjetivo sustantivado con valor metonímico: el lugar por las características de su creación. Se ha producido por elipsis de «sociedad cooperativa».

LA FÁBRICA.

GRANJA (Granja de las Veinte, Granja de los Morenos). El término es un préstamo del francés grange, por medio del bagaje cultural de los monjes benedictinos, según señala J. A. Frago ${ }^{30}$. En nuestra zona, sin embargo, no son términos de antigua creación, ya que responden a lugares relativamente modernos. En el segundo término encontramos la referencia al lugar: las Veinte, o bien al sobrenombre de la familia: los Morenos.

EL MOLINILLO.

EL POLIDEPORTIVO.

EL SEMINARIO: el sentido que tiene en la zona es el correspondiente a seminario conciliar: "Casa destinada para la educación de los jóvenes que se dedican al estado eclesiástico» (DRAE, s.v.).

VENTA (Camino de la Venta, Venta del Calero, Venta de Belico, V. de las Perdices, V. Alemania, V. Urbano). Su sentido es «casa establecida en los caminos o despoblados para hospedaje de los pasajeros» (acepc. 3a del DRAE). En la actualidad algunos de ellos siguen conservando dicho valor. 


\subsection{Instituciones.}

Sólo tres topónimos están relacionados con este aspecto:

LA CARIDAD: Como nombre propio se refiere a una institución cristiana que se dedicaba a practicar dicha virtud y socorría a los pobres. Así se refiere a un terreno con su casa, que dejó a esta institución en herencia su propietario.

CONCEJO (Pozo del Concejo). Corresponde a una de las instituciones que regían la vida del municipio.

JUNTA (Puente de la Junta). Tienen el sentido de «conjunto de los individuos nombrados para dirigir los asuntos de una colectividad» (acep. 5. del DRAE).

\section{Cuestiones Fonéticas.}

Hemos señalado los términos respetando la norma académica, con lo cual es necesario ahora indicar cuáles son las notas fonéticas que predominan en el habla de Pilas y afectan, pues, a dichos topónimos. Trataremos sólo aquellos fenómenos que se producen en estos nombres.

4.1. En el consonantismo en posición inicial, cabe anotar los siguientes casos:

- Evolución de la F inicial: en todos los topónimos ha seguido la solución castellana, excepto en Fontanar que es un arcaísmo, ya que conserva esta consonante, cuando debería haber dado hontanar.

- H-: se aspira como en todos los apelativos. Es nota característica andaluza. Así, hoyo se pronuncia / hojo/. Hambre también se aspira, llegando casi a una velar $/ \mathrm{x} /$. Eso permite la utilización del artículo femenino, ya que no se produce confluencia fonética de $a$. Otras veces, cuando el sonido vocálico inicial es $u e$, la $w$ se consonantiza y se confunde con la secuencia gwe. Así en huerto la pronunciación se realiza con esta velar.

- Pérdida de la primera sílaba, ya sea vocal: nana por enana; vivilla por abubilla, o consonante: dehesa $>$ hesa $>$ jeza. En este último también se ha producido un ceceo, como veremos.

4.2. En la posición interior se sitúa la mayoría de los fenómenos:

- Epéntesis antihiática: Abulagar por aulagar.

- Epéntesis nasal: Mensonera por mesonera, como ultracorrección de una asimilación originaria.

- Pérdida de la - $d$ - intervocálica: verea por vereda, cercao por cercado, ca$\tilde{n} a ́$ por cañada, vaera por vadera. Sin embargo, se conserva en el topónimo: La Caridad. Este mismo término, usado como apelativo, se pronuncia, en cambio, sin $d$ : cariá. Esto puede obedecer a que se refería a una institución religiosa y por ello se impone la evolución culta.

- Neutralización de líquidas en intervocálica:

-r-> -1-: alanzá por aranzada.

Y en implosivas: -1- >-r-: mergarejo por melgarejo.

Asimilación -rl > -rr-: Berranga por Berlanga.

- Aspiración de la -s implosiva: Mari ${ }^{h}$ ma por marisma. 
4.3. En posición final se suprimen todas las consonantes: Caridá por caridad, Fontaná por Fontanal, Chaparrá por Chaparral, Resina por Resinas. Sin embargo, en $d e l$, esa - $l$ se trata como intervocálica, ya que el sintagma se toma como un grupo fónico y el fenómeno opera al final del grupo, y no en final del término. Así en Hoyo del Huerto es /xójo:R gwéRto/. Y en Fuente del Puerco: /fweNte: R pweRko/. Y, al llevar $d$ y $l$ dicho tratamiento intervocálico, las vocales se asimilan.

- La -s final se aspira cuando tiene pertinencia morfológica, pero sólo en el artículo, evitando toda redundancia. Así la ${ }^{\mathrm{h}}$ Cruce, La ${ }^{\mathrm{h}}$ Mariana...

4.4. Como fenómenos generales hay que señalar el ceceo y el yeísmo, caracterizadores de la fonación andaluza y constitutivos de la norma en el habla de Pilas. No hay distinción, ni siquiera fenómenos de ultracorrección. Estas neutralizaciones afectan a toda $/ \mathrm{s} /, / \theta /, \mathrm{y} / \lambda /, / \mathrm{J} /$, estén en la posición en que estén. Así, el ceceo puede ser detectado en posición inicial en / $\theta$ ejorita/ por /se łorita/.

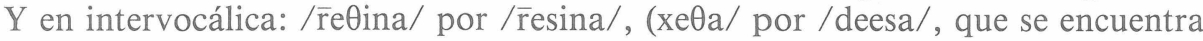
incluso en documentos ${ }^{31}$. Esto llega a provocar ambigüedades, en casos como Roza Alta, que podría interpretarse como el sustantivo deverbal roza o como rosa, flor.

El yeísmo también es regla normal: / $\theta$ antiján/, /ciǰa/...

\section{Procedimientos de formación de palabras.}

Dentro de este capítulo, lo más importante es la sufijación mediante diminutivos. En el resto concuerda con las características del español hablado. Dicha creación de diminutivos presenta una enorme variedad. Así aparece -illo, - $a(<-$ $\breve{E L L U), ~ s u f i j o ~ d e ~ g r a n ~ d i f u s i o ́ n ~ y ~ c o n s e r v a d o ~ e n ~ s u ~ f o r m a ~ m o d e r n a . ~ L o ~ t e n e m o s ~}$ en los siguientes topónimos: cabillo, Campillo, Caracolillo, Casilla (este ya gramaticalizado e incluido en el lexema base), perrillo, Pililla, Molinillo, Lamparilla y Veredilla.

De la forma -ITTU, y por influencia mozárabe apareció -eto, - $a$, según defienden Alvar y Pottier. Estos autores piensan que habrían sido posible una evolución a -eto en Al-Andalus, mientras que en la zona pirenaica, donde abunda, tendría su evolución normal a -et. De este sufijo tenemos tres casos: Caldereta, Norieta y Vareta. Por lo tanto, o se admite su origen mozárabe o sería una muestra de la implantación de un sufijo-nor-oriental en el sur de Andalucía. Sin embargo, está tan extendido en Sevilla y Huelva, que cabría pensar que se trata de un sufijo de implantación general, que en el Siglo de Oro se fragmentó y fue aquí menos frecuente que en el oriente peninsular.

Sigue en importancia el sufijo -ito, $-a$, procedente del mismo origen, que encontramos en Capotito y Señorita. De enorme difusión y de origen incierto, «tiene un carácter minoritario o de nula presencia» ${ }^{32}$. Sin embargo, como procedimiento de creación léxica, es el de mayor uso en el habla de la zona.

31 Heza en un doc. de 1734, folio 37a, línea 7, en «Libro de Fincas...» ya citado.

32 M. Alvar-B. Pottier: Morfosintaxis histórica del español, Madrid, Gredos, 1983, p. 373. 
De -ino, in (<-INU), diminutivo de origen leonés tenemos dos casos: Roba(d)ina y Ventolines, plural de un supuesto ventolín, creado sobre ventolina. Según Alvar y Pottier la implantación de este sufijo sólo es ocasional o bien «responde a lexicalizaciones cumplidas en épocas anteriores ${ }^{33}$. Eso habría ocurrido en el primer caso, ya que el sufijo -ina ahí no tiene valor diminutivo y podría entenderse como un creador de sustantivo del adjetivo robada, como ya dijimos en el apartado correspondiente.

Otro sufijo de menor extensión es -ejo (<-ICULU) y su variante andaluza -ajo ${ }^{34}$. Contamos con dos casos: Melgarejo y Regajo. El sentido que tiene este sufijo es depectivo. En Melgarejo se produce una acumulación de sufijos: ar, abundancial o colectivo, y sobre este el despectivo.

De -uelo (<-ÖLU) sólo hallamos un caso: pozuelo, sufijo menos usado y que se conserva en la forma tradicional. Igual ocurre con -ico. Sólo lo tenemos en Perico, diminutivo a partir de Pero, forma medieval de Pedro.

\section{Referencias extralingüisticas.}

En este corpus, objeto de nuestro estudio lingüístico, han quedado huellas de aspectos situados fuera de este ámbito, ya que el material por su propia naturaleza se presta a la conservación de situaciones muy antiguas. Sólo algunos, los más evidentes, quedarán señalados aquí, como un bosquejo de lo que la toponimia puede aportar al historiador.

Encontramos en él referencias socioculturales muy importantes. Por ejemplo, quedan huellas del antiguo régimen de explotación de la tierra, por latifundios y forasteros, como ha demostrado E. Camacho en su estudio de Pilas ${ }^{35}$. Así, la Huerta del Marqués, la Cañada de Don Luis, Los Montes de Doña Isabel, Estacada de Resinas... En ellos se hace mención a antiguos propietarios, ya sean referidos a la antigua nobleza: el Marqués, o de gran importancia socio-económica: Don Luis, Doña Isabel, D. Fco. José Resinas. Al mismo tiempo, el sistema social se refleja en el uso de los términos: frente al don de las designaciones anteriores, el artículo que se usa vulgarmente con los nombres de personas, o, generalmente, con el sobrenombre con el que se conoce en el pueblo a la familia: Don Luis / la Pitifla.

Hay otros topónimos que dibujan a grandes rasgos la vida cotidiana de épocas anteriores: así El Pozo del Concejo, la Fuente del Puerco, El Puente de la Junta. Como contrapartida, unos de creación más reciente, denotan la evolución en la vida: Castilla de la Vía, la Cooperativa, al Fábrica... Y huellas de emigración: Venta Alemania.

Por otro lado, en numerosas ocasiones el hablante ha perdido conciencia de la motivación de los topónimos, al desaparecer la realidad que los produjo: la

33 Ídem, p. 371.

34 Ídem, p. 370.

35 E. Camacho, en las dos obras citadas. 
Cámara, Cinco Eras, El Pilar, El Cerro del Grullo, Feria... Otras veces existían antiguamente dos zonas contiguas con dos denominaciones distintas, que hoy se han igualado convirtiéndose estas en meras variantes: así El cerro de los Piojos - El Barrio de las Varetas.

También el folklore tiene un puesto importante en la creación de topónimos. Y así nos encontramos con los Judíos, que, al parecer, vienen de una tradición antigua. De carácter popular es también la Hambre, con valor metonímico, como explicamos. Tiene marcado valor sociocultural, como huella de la aventura americana, el Perú. O la Estacada del Gallego, como signo de repoblación. Por último, Gitana y Los Judíos aluden a la convivencia con otras razas, propia de nuestra cultura hispánica.

Todo esto está en consonancia con lo que los estudios de la toponimia vienen a señalar: es una disciplina importante tanto para la historia como para la lingüística.

\section{Conclusión.}

No ha sido nuestra intención analizar de forma exhaustiva todo el material ofrecido. Creemos que es necesario tener más datos de otras zonas de la provincia, y del resto de Andalucía, para poder compararlos y llegar a unas conclusiones fiables. Sólo pretendemos exponer una documentación que sirva para avanzar en este tipo de investigaciones, un tanto desatendidas en nuestra bibliografía lingüística. 
